\title{
GEOGRAPHIC FEATURES AND ENVIRONMENTAL CONSEQUENCES OF COFFEE TOURISM AND COFFEE CONSUMPTION IN BUDAPEST
}

\section{LÓRÁNT DÉNES DÁVID ${ }^{1 *}$, BULCSÚ REMENYIK², GOGO FREDRICK COLLINS ADOL ${ }^{3}$}

${ }^{1}$ Szent István University, Institute of Supply Chain Management, Marketing and Tourism, Department of Tourism and Hospitality, Gödöllő

${ }^{2}$ Budapest Business School, Department of Tourism, Budapest

${ }^{3}$ Szent István University, Faculty of Economics and Social Sciences, Gödöllő

*Email: david.lorant.denes@szie.hu

Received 20 March 2021, accepted in revised form 12 April 2021

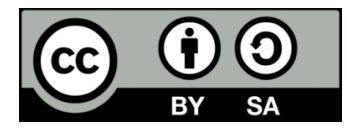

\begin{abstract}
As a survey by the Hungarian Central Statistical Office (2019) confirms coffee is consumed in 83\% of Hungarian households, thus our country can be considered to be one of the major coffee drinking nations. At the end of the 19th century and the turn of the twentieth Budapest with its internationally famous and unique coffee culture was known as the coffeehouse capital. Post-modern tourism revived this tradition and coffee became once again a favourite consumer item while cafés turned into scenes of community life. The latest stage of the coffeehouse renaissance was partly due to the increasing role of American type café chains including McCafé, Starbucks, California Coffee Company etc. and the drop in the price of the Arabica coffee. Our research focuses on the impact of this new type of coffee consumption wave on the coffee habits of Hungarians. The American café chains have become widespread in Europe and their ability to keep the price of coffee low worldwide demonstrates significant market power. While coffee consumption has several benefits from a physiological point of view, its environmental impact is detrimental to the planet. Coffee cultivation contributes to the destruction of rainforests, the changing of the soil and last but not least results in a high amount of solid waste due to the popularity of coffee capsules. Our treatise explores these concerns as well.
\end{abstract}

Keywords: coffee tourism, coffee consumption, environmental impact, Budapest

\section{Introduction}

Coffee was introduced in Hungary during the Turkish Conquest as cafés had already been in use in the Ottoman Empire in the 16th century. The first coffeehouses were established in Buda under the rule of Sultan Suleiman.

The second renaissance of coffee tourism took place in Budapest at the end of the 19th century as coffeehouses became social centres. Presently only a few remodelled historical coffeehouses are operational with the Central, the New York, and the Hadik House serving customers at their original location. All coffeehouses had to adapt to the requirements of the postmodern age assuming fully new functions compared to their original purpose. The Central Coffeehouse developed a strong restaurant 


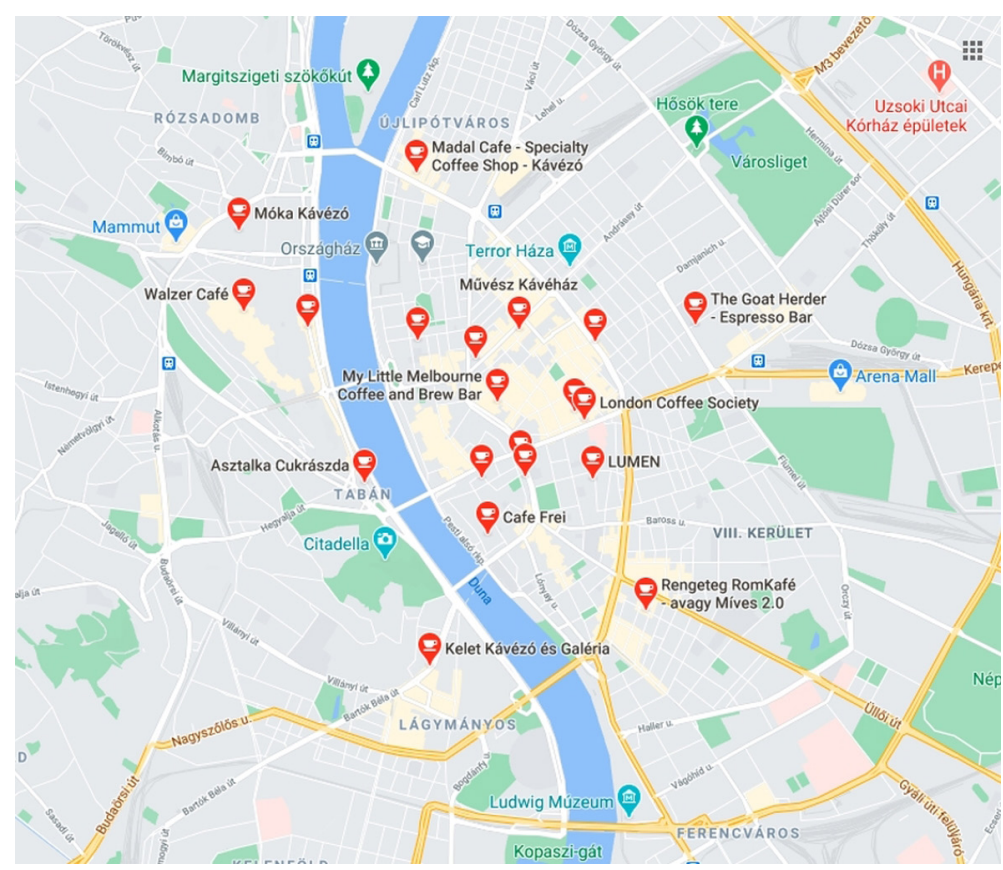

Fig. 1. Café locations in Budapest (google maps 2020)

profile primarily addressing the locals and become one of the tourist attractions offered by the capital. As part of a luxury hotel the New York turned into a social hub for foreign tourists, and the alternatively revived Hadik Coffeehouse was divided into two parts providing various attractions to young and old visitors, along with local and foreign tourists. Several of the established confectioneries, the Auguszt, the Szamos, or the oldest one in Budapest, the Russwurm assign a high role to coffee consumption in their business profiles as well.

The current revival of coffee tourism in Budapest is mostly due to the appearance of American café chains in the domestic market. While Starbucks and McCafé have the highest customer and sales figures, Costa Coffee, California Coffee Company, and the Coffee Shop Company are strong rivals. The new type of cafés, which primarily serve a young clientele, are located in Central Budapest, near the major universities and other areas with heavy foot traffic (Fig. 1).

By coffee tourism we mean a new type of tourism product that combines the offerings of the 21st century new wave cafes with the coffee culture of 19th century Budapest. The product is aimed at young people and includes cultural and artistic performances.

\section{Material and Methods}

Focusing on coffee as a touristic product, we have performed both secondary and primary research in context of the respective material and methods. Coffee tourism intends to familiarise visitors with the international coffee consumption culture via the combination of attraction components with this beverage (Kleidas-Jolli, 2010). While coffee tourism is considered an important component of agro-tourism by the international research literature (Lyon, 2013), certain authors consider it as part of gastro-tourism (Kleidas-Jolli, 2010). The main economic benefits of coffee tourism include providing a stable source of income for coffee farmers in tropical regions (KarlssonKarlsson, 2009) along with promoting a willingness to visit coffee producing regions far from Europe (Setiyorini, 2018). Coffee has a magical capability to transport its drinker to Brazil, Vietnam, or Kenya without leaving 
one's home (Anbalagan-Lovelock, 2018).

The primary research included a survey of 340 young people in our practice hotels in Hungary, and in the United States in Broadmoor and See Island concerning the potential impact of American cafés on the coffee consumption culture in Budapest.

The development of postmodern coffee tourism in Budapest is based on the fact that members of the $\mathrm{Y}$ and $\mathrm{Z}$ generation spend more than $50 \%$ of their income on services. $90 \%$ of the respondents frequents coffeehouses with a group of 2-5 and 94\% of the groups are composed of friends and acquaintances, $3 \%$ visits cafés with other family members, and $2 \%$ were married couples. Respondents consider the image of the venue as the main attraction along with the developed international brand and the accessibility of the given facility. $43 \%$ of the respondents revealed that they consume coffee twice a day. 23\% drink three or four times a day, $3 \%$ five or six times a day, and $2 \%$ enjoys this beverage more than 6 times a day. Hungarians tend to frequent cafés after lunch or in the afternoon hours (Fig. 2).

While both countries are considered major coffee consumers, Figure 3 confirms that cafés are more popular in the United States while Hungarians tend to prefer drinking coffee at home.

For Hungarians it is more important that a coffeehouse is comfortable (Figure 4) as most of them like to sit down and spend a longer

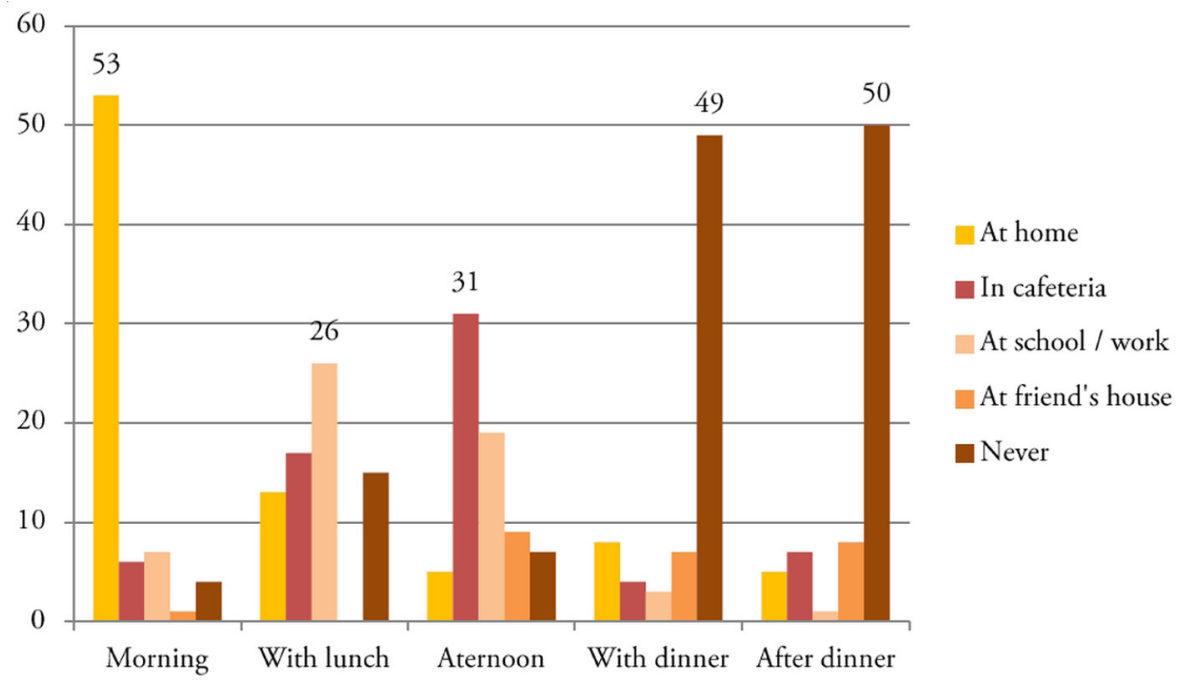

Fig. 2. Where do you drink coffee at certain times of the day?

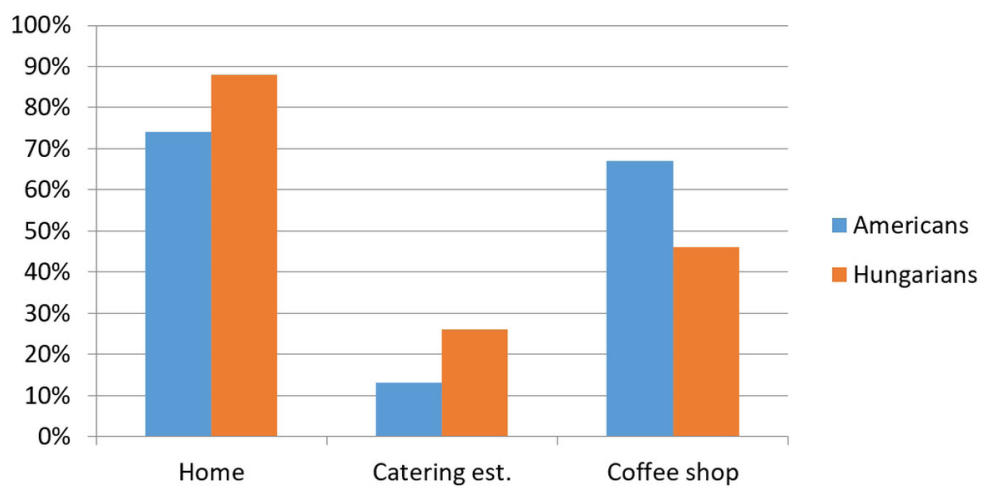

Fig. 3. Where do you drink coffee most often? 


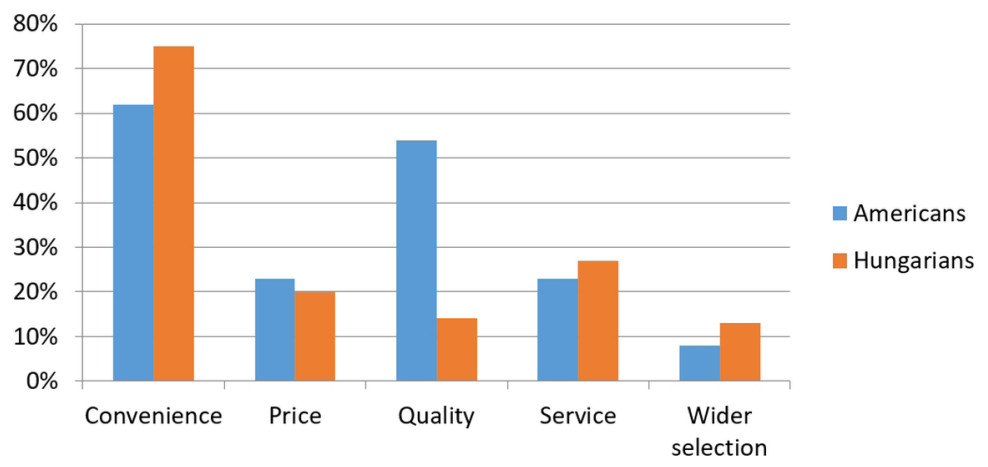

Fig. 4. Factors determining the selection of cafés

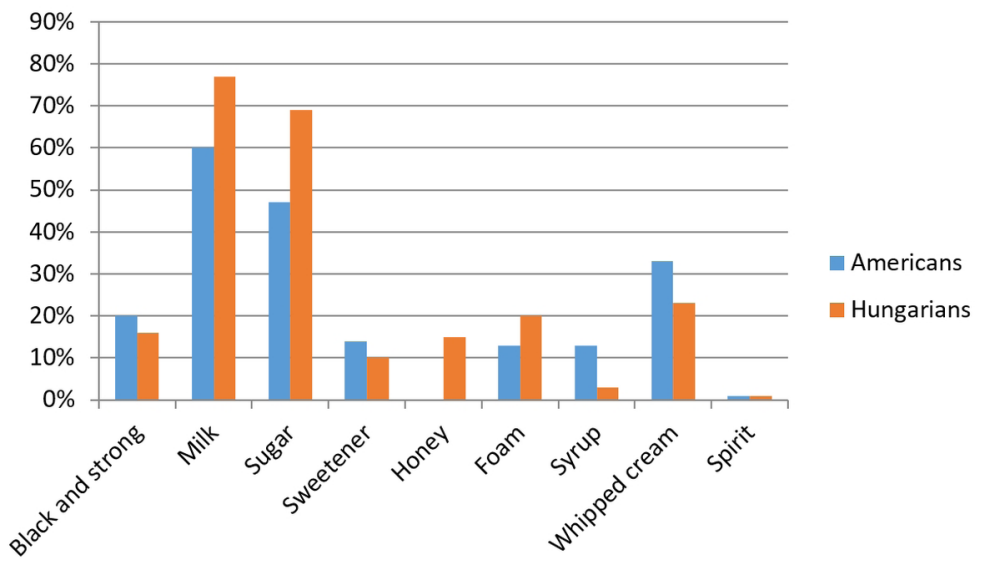

Fig. 5. How do you drink your coffee?

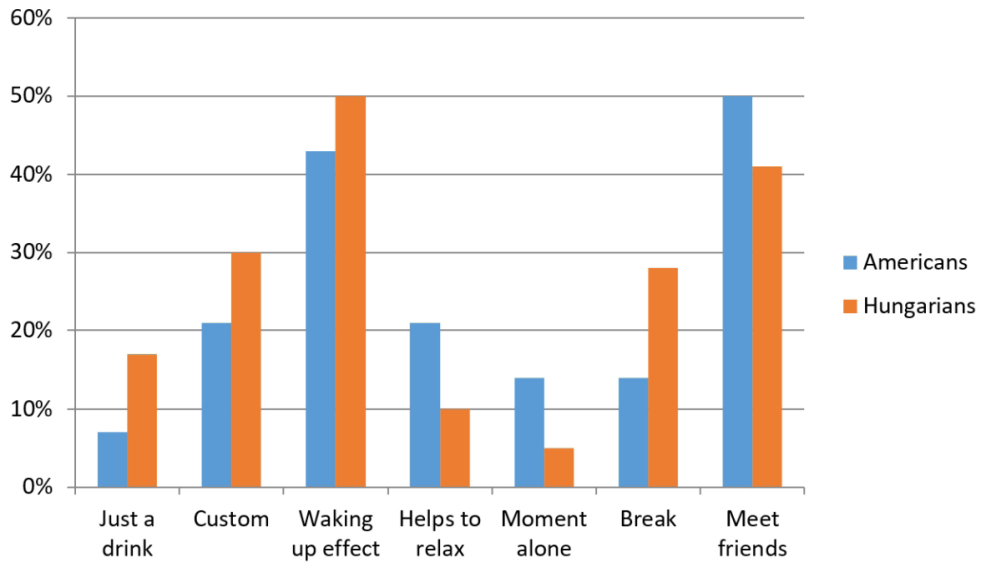

Fig. 6. Why do you drink coffee and how does it help you?

time there, while Americans rather ask for coffee to go. $80 \%$ of Hungarian respondents preferred sitting down by a table at a café and $67 \%$ of American respondents chose to take coffee with them. It is noteworthy that price is not a major factor concerning the selection of the cafés as Americans emphasize quality (54\%) and Hungarians appreciate the wide selection.

Figure 5 shows that the Americans tend to insist on consuming coffee in a healthier way as they tend to favour other sweeteners 
instead of milk, whipped cream and sugar. Nevertheless, they are not familiar with another healthy way to sweeten coffee, the use of honey.

Figure 6 shows that Hungarians consider coffee consumption as a break from daily tasks, while in America people frequent cafés in order to meet friends.

Almost $80 \%$ of respondents wrote that the quality of coffee is very important to them. In terms of coffee supply, cafes should also sell light and dark roasted coffee. According to our survey, guests do not primarily decide which cafe to consume based on their selection. However, in addition to espresso coffee, it is important to include the main elements from the ristretto to the latte with caramel syrup.

\section{Discussion: environmental aspects}

The rising popularity of coffee tourism contributed to global warming. In the discussion segment we explore how the coffee plant (along with the cocoa) can be held responsible for the greenhouse effect.

Due to the worldwide growth of coffee consumption coffee plantations tend to take up an increasingly larger percentage of tropical rainforests. Some researchers assert that such developments greatly contribute to global warming (Gibbs 2018). In case of the jungles of Ghana and the Ivory Coast $80 \%$ of the vegetation was burned in order to make room for coffee and cocoa production (Pearce 2019). The carbon dioxide emitted from the burning trees resulting from the deforestation practices increases the global release of harmful materials by $8 \%$ (Gibbs 2018).

Next to cattle raising coffee cultivation has the second largest ecological footprint as the production of $1 \mathrm{~kg}$ coffee results in 16 $\mathrm{kg}$ gas contributing to the greenhouse effect. (https://interactive.carbonbrief.org/whatis-the-climate-impact-of-eating-meat-anddairy/).
Bobcsák asserts that this situation results from the use of a high amount of nitrogenbased fertilizers in order to make the laterite soil suitable for coffee growing and to increase the crop yields (Bobcsák 2011). Although the decline of the rainforests leads to the production of less oxygen, its long term effect on the Earth's atmosphere has not been assessed yet.

The preference of the new type of cafés for easy to store coffee capsules made from the combination of plastic and aluminium leads to a significant environmental hazard since an appropriate recycling procedure hasn't been developed yet. The processing of the continuously growing capsule mountains is expected to take decades (https://greenfo. hu/hir/kornyezeti-bomba-a-kavekapszula/). One of the most often quoted figures demonstrating the respective threat to the environment originates from 2018.

Proving that coffee has the largest carbon footprint, Bobcsák calculates that the production and processing of traditional coffee results in the highest carbon-dioxide release $(0,140 \mathrm{~kg} / \mathrm{cup})$ followed by capsule coffee $(0,092 \mathrm{~kg} / \mathrm{cup})$ and freeze-dried coffee (0,068 kg/cup) (Bobcsák 2011).

The smallest ecological footprint is caused by espresso and the largest segment of Hungarians surveyed in the cafés (34\%) prefer to drink this type of coffee.

After oil coffee is the second most important global commodity. While there are 125 known coffee species on Earth, only one is suitable for human consumption. The Arabica coffee originates from Ethiopia, but it cannot survive in high temperatures.

(https://www.napi.hu/tozsdekpiacok/ ha_ez_igy_marad_elfogy_a_kave_a boltokbol.660996.html)

In summarizing the previous arguments, it can be concluded that the global demand for coffee cannot be satisfied by keeping the prices of the Arabica coffee at such a low level. 


\section{Summary}

Coffee tourism means more than coffee consumption in order to increase our physical awareness and improve work performance. While consumption has several benefits including raising blood pressure and expanding blood vessels and reducing the formation of gallstones, drinking large amounts can lead to addiction. (http://ecolounge.hu/eletmod/kave-esfenntarthatosag)

We must conclude, however, that the return of the coffeehouse revival of the turn of the twentieth century cannot be expected. The famous and established coffeehouses have changed their original profiles and the latest trends and market developments promote the American coffee culture. In light of the abovementioned factors we attempted to explore the potential developmental directions in coffee tourism in Hungary. In our view, the American café chains based in Hungary have generated an overall positive effect on domestic coffee consumption. Furthermore, in order to deal with the resulting high amount of solid waste a new souvenir industry emerged. The disposed coffee capsules thus can be turned into rings, necklaces, ear rings, along with lamps, refrigerator magnets, flower pot holders and plastic room partition curtains.

The other positive aspect of American style coffee consumption is the limited use of sugar and cream while the negative side entails the significant number of plastic cups used for take away coffee. Unfortunately, not even cups made from bamboo could provide an effective remedy against plastic pollution.

Further research efforts could focus on alternative ways of utilizing coffee including the use of green coffee in the cosmetics industry and health tourism.

\section{References}

Anbalagan, K. - Lovelock, B. (2018): The potential for coffee tourism development in Rwanda - Neither black nor white. Tourism and Hospitality Research. 12/34. pp. 171-186.
Bobcsák, G. (2011): A környezeti, társadalmi és gazdasági életcikluselemzés alkalmazhatóságának a vizsgálata - avagy mekkora ökológiai lábnyomot ró a környezetre egy csésze kávé elfogyasztása? (The feasibility of environmental, social, and economic life cycle analysis-what is the size of the ecological footprint resulting from the consumption of a cup of coffee?) http://www.tdk.uni-miskolc. hu/files/20111107_101153459.pdf

Gibbs, D. et al. (2018): By the Numbers: The Value of Tropical Forests in the Climate Change Equation. https://www.wri.org/ blog/2018/10/numbers-value-tropicalforests-climate-change-equation

Karlsson, H. - Karlsson, J. (2009): Coffe tourism. http://www.diva-portal.org/smash/get/ diva2:220789/FULLTEXT02.pdf

Kleidas, M. - Jolli, L. (2010): Coffee attraction experiens Vol. 58 No. 1/ 2010/ 61-73 UDC: 338.48-641/642

Lyon, S. (2013): Coffee Tourism and Community Development in Guatemala. Human Organization 72(3): 188-198.

Pearce, F. (2019): The Real Price of a Chocolate Bar: West Africa's Rainforests. Yale University. https://e360.yale.edu/features/the-realprice-of-a-chocolate-bar-west-africasrainforests

Setiyorini, D. (2018): Coffee Tourism Development Potential: Benefit and Consequences H. P. Diyah Setiyorini Tourism Marketing Management Advances in Social Science, Education and Humanities Research.

Trinh, L.T.K. et al. (2020): Comparative life cycle assessment for conventional and organic coffee cultivation in Vietnam. International Journal of Environmental Science and Technology volume 17, pages1307-1324.

https://interactive.carbonbrief.org/what-is-theclimate-impact-of-eating-meat-and-dairy/

https://greenfo.hu/hir/kornyezeti-bomba-akavekapszula/

http: / / ecolounge.hu/eletmod/kave-es fenntarthatosag

https://www.napi.hu/tozsdekpiacok/ha_ez_igy_ marad_elfogy_a_kave_a_boltokbol.660996. html

www.ksh.hu (Hungarian Central Statistical Office)

www.google.maps.org 